\title{
Measuring the Correlation Between Self-Efficacy Beliefs and English Language Attainments Among Thai University Students
}

\author{
Matthew Rudd \\ English Language Centre, Mahanakorn University of Technology, Bangkok 10530, Thailand
}

\begin{abstract}
This study examined the predictive value of Bandura's 100 point self-efficacy scales among 208 third year university students (female; $\mathrm{n}=108$, male; $\mathrm{n}=90$ ) from three separate faculties; veterinary medicine $(\mathrm{n}=60)$, business administration $(n=77)$ and engineering $(n=71)$ at a private institute of technology located on the outskirts of Bangkok. The central research question of this paper was to ascertain the extent to which one's self-efficacy beliefs in English language attainments correspond with respective performance outcomes. Respondents were required to indicate their levels of self-efficacy in English as a general subject, as well as in domain specific matters relative to speaking proficiency, mid-term tests and final examinations. The results showed that the predictive value of subject related measures of self-efficacy across the sample population proved to be highly accurate, as the means of both sets of results were not significantly different (S.E: $68.12 \%$ vs. English: $66.28 \% ; p<0.05$ ), and were closely correlated $(r=$ 0.692).The results from the domain specific scales, however, were less consistent. While there was no significant difference between declarations of self-efficacy and grade outcomes in both mid-term tests and final examinations (mid-term:62.59\% vs. 64.33\%; final: 63.22\% vs.64.24\%; p <0.05), and, both variables were also closely correlated (mid-term, $r=0.7018$; final, $r=0.686$ ); personal efficacy judgments for speaking proficiency were significantly inferior to respective attainments $(58.46$ vs. $68.25 ; \mathrm{p}<0.05)$; resulting in a weaker correlation $(\mathrm{r}=0.5248)$.
\end{abstract}

Keywords: self-efficacy, beliefs, performance, subject, domain

DOI: $10.7176 / \mathrm{JEP} / 10-5-09$

Publication time: February $28^{\text {th }}, 2019$.

\section{Introduction}

Self-efficacy concerns the judgments of one's abilities to organise and execute courses of action required to attain designated types of performance (Bandura, 1986), and, has been valued as a pivotal factor in influencing academic motivation, learning and achievement (Pajares, 1996); a claim this paper will empirically examine.

According to Bandura (1994) the development of self-efficacy is fostered on the grounds of perceived selfimprovement, rather than by interpersonal comparisons and triumphs over peers, and is acquired from four main sources. Firstly, mastery experiences are a significant contributor to one's personal beliefs and self-efficacy, and are an influential factor in guiding future endeavours. Successful mastery experiences solidify belief in one's personal efficacy, whereas experiences associated with failure risk becoming sources of self-debilitation among those with low personal efficacy beliefs. Powerful mastery experiences that affirm one's capacity to affect personal changes "can produce a transformational restructuring of efficacy beliefs that is manifested across diverse realms of functioning" (Bandura, 2006). This suggests that the development of self-efficacy beliefs and competencies may concurrently develop across unrelated spheres of activity (Bandura, 1997); as they are often governed by similar underlying subskills. The differentiating factor between those with high and low levels of self-efficacy is the self-regulatory robustness to persevere in the face of adversity, to resist the debilitating effects of failed attempts, and, to recover from failure; with the firm belief that efforts can be purposefully redirected and intensified (Bandura, 1994).

Secondly, beliefs can also be reinforced (or undermined) through vicarious experiences (social modelling). Witnessing successful models that have displayed tenacity and exemplary capabilities in their fruitful attempts instils belief in the observer that this successful attempt can be replicated with persistence and effort (Bandura, 1996). On the contrary, observers of models displaying negative outcomes, irrespective of the level of effort invested, usually experience increased disbelief in their own capabilities as a result of the model's failure. The effect of modelling is especially influential if the perceived similarity between the observer and the model is strong.

Thirdly, social persuasion can serve as a significant source of reinforcement or discouragement in one's personal beliefs depending on the nature of persuasion (positive or negative). Regrettably, individuals are more greatly affected by negative talk, injurious to their beliefs, than persuasion attempts to reinforce their beliefs (Bandura, 1994). The fourth source of beliefs of personal efficacy comprises emotional states and the ability to manage somatic reactions. Frame of mind also affects individual judgments of personal efficacy, as positive mental disposition enhances perceived self-efficacy; "people who have a high sense of efficacy are likely to view their state of affective arousal as an energizing facilitator of performance" (Bandura, 1994). Conversely, a depressed somatic state destabilises beliefs of personal efficacy among those overwhelmed by self-doubt.

Self-efficacy is channelled through the four main psychological mechanisms known as self-efficacy activated processes (Bandura, 1994). Cognitive processes mentally conceive and strategise courses of action, as well as anticipate the potential outcomes of these events. Scenarios constructed on the basis of higher efficacy beliefs are likely to envisage fruitful outcomes supported by a detailed plan of action to navigate potential uncertainty, founded on the basis of knowledge acquired from prior experiences; derived from both mastery and failure.

Motivational influences greatly affect the manner in which tasks are approached, and, endeavours are sustained 
through self-evaluative reaction to one's own performance. Motivation to persevere until desired outcomes have borne fruit is a cognitively generated process, namely through goal setting supported by a plan of action. The level of selfefficacy is likely to determine the ambition of these goals, the amount of time and the level of effort invested, as well as the tenacity of willpower to accomplish desired objectives.

Third of all, affective processes refer to the extent to which individuals' coping efficacy helps to resist stressors and maintain efficacious levels of functioning. Bandura (1991a) also posits that a strong sense of coping efficacy helps resist depressive states; "A low sense of efficacy to exercise control over ruminative thought also contributes to the occurrence, duration and recurrence of depressive episodes". Further to mental disposition, given the interdependence of biological systems, coping efficacy can also fortify immune health. A distinction must be made between the inability to resist the impact of stressors that undermine immune function, and, a situation in which the encountered stress contributes to the process of strengthening coping efficacy; which is vital for evolutionary adaptation and selfprotective capabilities (Bandura, 1994). Finally, selection processes are majorly influenced by beliefs of personal efficacy and can instrumentally shape people's itinerant behaviour by influencing the types of activities and environments people select; "by the choices they make, people cultivate different competencies, interests and social networks that determine life courses", (Bandura, 1984).

\subsection{Measuring perceived self-efficacy beliefs}

Perceived self-efficacy is concerned with people's beliefs in their capabilities to produce given attainments (Bandura, 1997), and the areas in which people cultivate their efficacy beliefs, as well as the degree to which these beliefs are developed vary according to the individual, and their respective pursuits. Theoretically, those that rate their perceived self-efficacy highly are expected to differ in their regulatory behaviour from those who declare weaker efficacy levels (Bandura, 2006). Bandura theorises that the probability of successful performance can be computed as a function of the strength of perceived self-efficacy (Bandura, 1977). However, Bandura (2006) stresses that there is no feasible allpurpose means of measuring self-efficacy, given that the one-measure-fits-all approach usually offers limited explanatory and predictive value. This is because in a generic test, the majority of items may bear scant relation to the domain of functioning being measured, and fail to take into account the circumstantial and situational demands.

Levels of self-efficacy are more efficiently measured if efficacy scales focus on a specific domain of functioning, as it facilitates the identification of patterns of strengths and limitations in perceived ability (Bandura, 2006). Pajares (1996) maintains that task-specific measures are superior given that mastery of distinct skills is necessary to perform in certain domains; for example, mathematics requires the ability to calculate and interpret fractions, sums of division and long multiplications etc. Bandura (2006) adds that this type of refined assessment not only increases predictiveness, but provides guidelines for tailoring programs to individual needs. Items in self-efficacy scale surveys should question what participants can do rather than will do, given that can denotes a judgment of capability, whereas will is a statement of intention. Although perceived self-efficacy is undeniably a central determinant of intent, the two constructs are separable (Bandura, 2006). Further to which, perceived self-efficacy must be distinguished from other constructs such as; self-esteem (appraisal of self-worth), locus of control (the hypothetical level of control one's actions exert over determining the outcome of a given pursuit), and outcome expectancies (the value placed on the outcome).

Self-efficacy scales present items with different levels of task demands, and respondents rate the strength of their belief in their ability to successfully perform the corresponding task on a 100-point scale (Bandura, 2006). A 100 point scale response format (measured in units of ten) is a stronger predictor of performance than those consisting of only a 5-interval scale (Pajares, Hartley, \& Valiante, 2001). This is founded on the assumption that people generally prefer to avoid allocating extreme values to their capabilities, thus a scale consisting of a narrower continuum may risk limiting the variability of responses, and thus, the accuracy of data.

Self-efficacy questionnaires are conducted privately (without personal identification), and, respondents are assured that data is to remain confidential. The practical value for institutions being capable of building a sense of efficacy in its students can contribute to establishing further guidelines for structuring experiences which enable people to realise desired personal and social changes (Bandura, 2006). In the case of this paper, should self-efficacy scales prove to be a valid construct of predictive utility in relation to English language performances, carrying out selfefficacy scales could perhaps become indispensable routine procedure in order to identify and address potential weaknesses, strengths, low-confidence areas among students; as well as faults within the curriculum.

\section{Review of related studies}

The first study for review was presented at the New Researchers / Student Conference held at the University of Warwick (Web-Williams, 2006; Cambridge University press), which focused on self-efficacy in the classroom at primary school level. The research objectives included: (1) examining the relationship between self-efficacy and academic performance in science, (2) reviewing the impact of different levels of specificity of efficacy measures, and (3) to evaluate the role of gender within the established parameter.

A sample cluster of 50 students aged 10-12 (24 girls, 26 boys) completed a Likert scale (1-7) efficacy questionnaire to canvass the correlation between academic performance and students' efficacy beliefs for: (a) general academic achievement (English, mathematics, science: $\mathrm{r}=0.64$ ); (b) self-regulated learning (study habits and attitudes: $r=0.65$ ); (c) general science attainment (confidence in grade outcomes: $r=0.60$ ); (d) domain specific to science (e.g. 
health, plant growth: $r=0.65$ ); and (e) task specific to science (describing relationships and plant growth: $r=0.72$ ). The results inferred a strong correlation between the two variables; and the more specific the measure of self-efficacy, the stronger the correlation. Furthermore, girls scored significantly higher than boys in all measures of self-efficacy and academic performance.

Gender variations in this study also corresponded with those noted in Frank Pajares' research findings (1999, 2001). Britner and Pajares (2001) researched a sample of 262 seven $^{\text {th }}$ grade pupils, and found that girls displayed higher levels of self-efficacy, and subsequently, scored higher on science tests. In a similar vein, with respect to writing skills (concerning L1 attainments), Pajares and Valiante (1999) aimed to discover the extent to which selfefficacy judgments for writing were consistent with respective performances. At both elementary and middle school levels, girls outperformed boys in writing assessments despite reporting equal levels of writing self-efficacy. Interestingly however, inter-peer comparisons specific to gender revealed that girls believed themselves to be more highly skilled writers than their male counterparts; whereas boys' beliefs were shyer in this regard. Nonetheless, theoretically speaking, the social cognitive model does not naturally grant females with enhanced agentic and motivating properties that would bestow them with more sustained levels of self-efficacy, (Bussey \& Bandura, 1999).

A more recent study was published in the journal of European Academic Research (2013) and looked to identify the relationship between self-efficacy and academic performance in the context of gender among Albanian students. The sample comprised 180 participants (60 students from each year level from one to three) and included 102 females and 78 males (mean age: 22 years) from two major universities in the Albanian capital, Tirana. Questionnaires were designed to measure levels of perceived self-efficacy in relation to academic performance on the basis of students' self-reported GPA. To avoid neutral bias, the efficacy scales were scored 1-4, and on average, females displayed lower levels of self-efficacy (2.67) compared to their male counterparts (3.06). In spite of this variance in self-efficacy beliefs, there was no significant difference in academic performance, as female students reported a marginally higher mean GPA of 7.75 in comparison to that of 7.45 declared by their male peers. Overall, the relationship between selfefficacy and academic performance allegedly correlated very closely $(\mathrm{r}=0.85)$.

In this context, the reasons accounting for the lower levels of self-efficacy reported by females may due to the notion that gender differences in social, personality, and academic variables may actually pertain to gender orientation, which concerns the students' stereotypic beliefs regarding gender (Eisenberg et al., 1996). Moreover, given the discussed behavioural variations according to gender, this paper will also examine the intervening influence of the gender variable in both self-efficacy beliefs and subsequent performance outcomes.

\subsection{The significance of this study}

The first question to put forth is whether the statistics reported from the above studies would have produced different results if calculated on the basis of 100 point scales, as opposed to a more limited continuum, which inevitably restricts variability. Pajares, Hartley, and Valiante (2001) maintain that 100 point self-efficacy scales are psychometrically stronger than Likert scale measures, and in this respect, Bandura (1997) elucidates that "including too few steps loses differentiating information because people who use the same response category would differ if intermediate steps were included"' (p. 44). Within this premise, this paper implemented Bandura's self-efficacy scales (0-100) to extensively explore the relationship between efficacy beliefs and English language performance in the field of EFL. Both subject and domain specific measures concerning English language attainments were scrutinised using t-tests and Pearson's co-efficient. Furthermore, to ascertain the influence of profile variables, statistical variations were also examined according to gender and academic background (veterinary medicine, business and engineering).

\subsection{Research questions:}

1. What are the population demographics in terms of: a) gender; and, b) field of study?

2. To what extent do self-efficacy judgments correlate with performance outcomes in (a) subject related measures (overall attainments in English), and, (b) domain specific measures (speaking proficiency, midterm tests and final examinations)?

3. Is there a significant variation in self-efficacy judgments and English language attainments according to profile demographics: (a) gender; and, (b) academic background?

\subsection{Hypothesis:}

1. Based on the literature reviewed, there is expected to be no significant difference between students' perceived capabilities and their respective English language attainments across both subject and domain specific measures.

2. There is expected to be no significant difference between self-efficacy judgments and English language attainments according to profile demographics.

3. A positive correlation is expected across all calculations.

\section{Methodology}

The participants in this study $(\mathrm{N}=208)$ comprised third year university students from a private higher education institute of technology located on the outskirts of Bangkok. The students were from three separate faculties; veterinary medicine $(n=60)$, business administration $(n=77)$, and engineering $(n=71)$. The sample cluster was also fairly 
balanced demographically (females, $\mathrm{n}=118$; males, $\mathrm{n}=90$ ).

All participants were issued self-efficacy questionnaires using a one hundred point scale, blocked in units of ten, with the corresponding letter grade displayed below each value. Respondents were required to circle the percentage score they felt corresponded with their attainment potential. To avoid ambiguity, questionnaires and demonstrations were issued in Thai. To ascertain student profiles, information pertaining to age, gender and field of study were required. However, to assure the respondents that surveys were anonymous and kept in confidence, (and for purposes of data retrieval), each questionnaire was assigned a unique code.

Consistent with the theory that domain specific self-efficacy questionnaires offer greater levels of predictive value (Bandura, 2006), the self-efficacy scales used in this research comprised questions related to English as a general subject and domain-specific questions. Task-specific questions would not be appropriate in this research paper, as students are not formally assessed in task-specific activities, and therefore may not possess adequate levels of familiarity to score personal efficacy beliefs. Using the scale $(0-100 \%)$, the questionnaire asked students to indicate the final grade outcomes in English they believed themselves capable of achieving. They were also requested to gauge their level of certainty in relation to all major forms of assessment; speaking tests ( $30 \%$ of overall grade), mid-term tests $(20 \%)$ and final examinations $(50 \%)$.

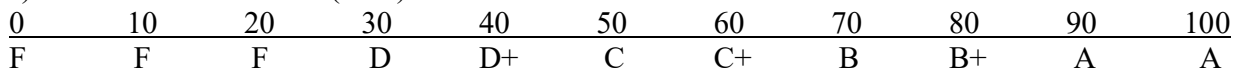

Formal examinations are a two-part assessment inclusive of reading, writing and grammar based questions. Seeing as self-efficacy questionnaires are designed to be distributed prior to assessment, respondents were required to complete the surveys in the third week of a 16 week term. Students were in their third year of study and had over two years' learning experience in accordance with the university syllabus, and were familiar with the demands of the course content and formal assessments.

The first assessment is the mid-term paper which takes place in week 8. Successively speaking tests are conducted in week 12, and final examinations in week 16. Mid-term and end term examinations comprise a similar nature of assessed tasks; however, both tests vary substantially in terms of their contribution to the overall grade, as well as temporal proximity. Within this parameter, it would be of interest to ascertain whether these two variables also intervene in self-efficacy judgments and corresponding performance outcomes.

Further to which, profile related data were collated in order to identify potential variations in self-efficacy and academic performance on the basis of gender and field of study.

It must be noted that further domain specific questions with respect to isolated macro skills were not included, given that they do not currently constitute forms of formal assessment at the university. Secondly, extra-curricular tests in specific macro skills would have to be conducted outside of regular teaching hours, as the university was rather reluctant to allocate valuable class time to additional forms testing. Thirdly, compelling students to surrender their free time in order to sit extra examinations for research purposes was deemed unethical; not to mention that anticipated low levels of attendance for non-mandatory tests would result in incomplete data.

\section{Findings/Results}

The first question set out in this paper was to clarify the student profiles. The number of third year students who completed the efficacy scale questionnaire, and for whom all performance related data was available totalled 208, (females: $\mathrm{n}=118$; males; $\mathrm{n}=90$; age bracket: 20-21 years). Although the demographic distribution appears relatively balanced as far as gender is concerned (56.7\% females; $43.3 \%$ males), when reviewing the demographics according to faculty, the demographics were rather unequal:
Vet medicine:
$\mathrm{n}=60$ students
females 42 ; males 18 (f: $70 \%, \mathrm{~m}: 30 \%$ )
Business admin: $\quad \mathrm{n}=77$ students
females 58 ; males 19 (f: $75 \%$, m: $25 \%$
Engineering:
$\mathrm{n}=71$ students
females 18 ; males 53 (f: $25 \%$, m: $75 \%$ )

This may be owed to the cultural labelling associated with certain academic disciplines, and the respective demographics of these disciplines are typically similar across most higher education settings in the country (public and private); thus demographic imbalances were unavoidable.

The major research question of this paper was to examine the relationship between students' self-efficacy beliefs and their respective grade outcomes; the accuracy of subject related measures is addressed first of all.

Table 1.A: the relationship between students' S.E and overall grade outcomes across the entire sample population $(\mathrm{N}=208)$

\begin{tabular}{|c|c|c|c|c|}
\hline Variable & M (\%) & P & Result & R \\
\hline S.E & 68.12 & & & \\
\hline & & 0.169255 & $\begin{array}{c}\text { Not Sig } \\
\text { p }<.05\end{array}$ & 0.692 \\
\hline Grade & 66.28 & & & \\
\hline
\end{tabular}

Table 1.A displays the mean values of students' self-efficacy beliefs in their English language attainments and their subsequent levels of performance. In general terms, the two sets of results were not significantly different ( $p$ $<0.05)$ and were strongly correlated $(r=0.692)$. This would infer that self-efficacy scales for subject related measures constitute an accurate means of gauging students' capabilities, and bolsters the theoretical ideology that efficacy 
beliefs offer reliable predictive value.

Table 1.B: the relationship between students' S.E and speaking proficiency

\begin{tabular}{|c|c|c|c|c|}
\hline Variable & M (\%) & P & Result & R \\
\hline S.E & 58.46 & & & \\
\hline & & $<.01$ & $\begin{array}{c}\text { Sig } \\
\mathrm{p}>.05\end{array}$ & 0.5248 \\
\hline Speaking & 68.25 & & & \\
\hline
\end{tabular}

As far as domain specific measures are concerned, Table 1.B reveals very dissimilar results to those observed in Table 1.A. Firstly, students feel less confident in their ability to deliver a satisfactory performance in their speaking assessments, and secondly, students' performance outcomes were significantly higher than that indicated in their selfefficacy judgements $(\mathrm{p}<0.05)$. As a consequence, the correlation of this domain specific measure $(r=0.5248)$ was notably weaker than on a subject related scale.

Table 1.C: the relationship between S.E and mid-term exam scores

\begin{tabular}{|c|c|c|c|c|}
\hline Variable & M (\%) & P & Result & R \\
\hline S.E & 62.59 & & & \\
\hline & & 0.19293 & $\begin{array}{c}\text { Not Sig } \\
\mathrm{p}<.05\end{array}$ & 0.7018 \\
\hline Mid-term & 64.33 & & & \\
\hline
\end{tabular}

Contrary to speaking assessments, the results displayed in Table 1.C support the notion that domain specific efficacy measurements can also serve as an accurate indicator of potential, as suggested by the highly positive relationship between students perceived levels of self-efficacy and mid-term test results $(\mathrm{r}=0.7018$; sig: $\mathrm{p}<0.05)$.

Table 1.D: the relationship between students' S.E and final exam results

\begin{tabular}{|c|c|c|c|c|}
\hline Variable & M (\%) & P & Result & R \\
\hline S.E & 63.22 & & & \\
\hline & & 0.325524 & $\begin{array}{c}\text { Not Sig } \\
\mathrm{p}<.05\end{array}$ & 0.686 \\
\hline Final & 64.24 & & & \\
\hline
\end{tabular}

Likewise, the revelation from Table 1.D is that students' efficacy beliefs concerning formal assessments appear to closely match their respective grade outcomes $(63.22 \%$ in contrast to $64.24 \%$; not sig: $p<0.05)$; and both variables were very correlative $(\mathrm{r}=0.686)$. Given the identically comparative results with Table 1.C (mid-term tests), the inferential remark is that the temporal distance, or the weight of assessment is not a significant factor in relation to judgments of self-efficacy or English language attainment.

The third research question in this paper was to examine the interplay of self-efficacy beliefs and English language attainment across profile demographics (gender and faculty).

Table 2.A: the relationship between students' S.E and grade outcomes according to gender

\begin{tabular}{|c|c|c|c|c|c|}
\hline Gender & Variable & $\mathbf{M ~ ( \% )}$ & P & Result & R value \\
\hline $\begin{array}{c}\text { Females } \\
(\mathrm{n}=118)\end{array}$ & S.E & 70.68 & & & \\
\hline & Grade & 69.49 & & $\begin{array}{c}\text { Not Sig } \\
\mathrm{p}<.05\end{array}$ & 0.7257 \\
\hline & S.E & 64.78 & & & \\
\hline $\begin{array}{c}\text { Males } \\
(\mathrm{n}=90)\end{array}$ & & & 0.14321 & $\begin{array}{c}\text { Not Sig } \\
\mathrm{p}<.05\end{array}$ & 0.6363 \\
\hline & Grade & 61.73 & & & \\
\hline
\end{tabular}

The data displayed in Table 2.A shows that the accuracy of self-efficacy judgments with respect to academic performance is comparable among male and female students (not sig: $\mathrm{p}<0.05$ ). Nonetheless, the difference between the two sets of means was narrower among females, which was reflected in the greater value of P $(0.32089$ compared to 0.14121$)$. Secondly, the results of the two variables were also more closely correlated among females $(r=0.7257$ compared to $r=0.6363$ ), suggesting greater accuracy in the relationship between their levels of perceived self-efficacy and English language attainments. Furthermore, females' academic performance was saliently higher, suggesting a greater level of engrossment and competence in the subject. 
Table 2.B: the relationship between students' S.E and speaking proficiency according to gender

\begin{tabular}{|c|c|c|c|c|c|}
\hline Gender & Variable & $\mathbf{M ~ ( \% )}$ & $\mathbf{P}$ & Result & $\mathbf{R}$ \\
\hline $\begin{array}{c}\text { Females } \\
(\mathrm{n}=118)\end{array}$ & S.E & 59.58 & & & \\
\hline & Speaking & 72.15 & & $\begin{array}{c}\text { Sig } \\
\mathrm{p}<.05\end{array}$ & 0.5024 \\
\hline & S.E & 57 & & & \\
\hline $\begin{array}{c}\text { Males } \\
(\mathrm{n}=90)\end{array}$ & & & 0.02905 & $\begin{array}{c}\text { Sig } \\
\mathrm{p}<.05\end{array}$ & 0.5486 \\
\hline & Speaking & 63.11 & & & \\
\hline
\end{tabular}

Table 2.B exposes further intricacies concerning self-efficacy judgments and speaking skills. The crossexamination of data pertaining to gender fails to elucidate the disparity between these two sets of results Notwithstanding categorically higher levels of English proficiency, the basic interpretation is that females are conspicuously more conservative in judging their capabilities relative to their speaking potential. This is implied in the minimal value of $P$, suggesting that the mean difference between efficacy beliefs and speaking proficiency are rather incongruent; ( $\mathrm{p}=<0.01$ for females, $\mathrm{p}=0.02905$ for males).

Table 2.C: the relationship between students' S.E and mid-term scores according to gender

\begin{tabular}{|c|c|c|c|c|c|}
\hline Gender & Variable & M (\%) & P & Result & R \\
\hline $\begin{array}{c}\text { Females } \\
(\mathrm{n}=118)\end{array}$ & S.E & 64.41 & & & \\
\hline & & & 0.19336 & $\begin{array}{c}\text { Not Sig } \\
\mathrm{p}<.05\end{array}$ & 0.729 \\
\hline & Mid-term & 66.71 & & & \\
\hline $\begin{array}{c}\text { Males } \\
(\mathrm{n}=90)\end{array}$ & S.E & 60.22 & & & $\begin{array}{c}\text { Not Sig } \\
\mathrm{p}<.05\end{array}$ \\
\hline & Mid-term & 61.22 & & & 0.6585 \\
\hline
\end{tabular}

Table 2.C shows that both female and male students' beliefs in their mid-term test scores closely mirrored their corresponding attainments in this domain specific measure. This is indicated in the fact that the means between efficacy beliefs and mid-term attainments were not significantly different (not sig: $p<0.05$ ); unlike the results discussed in Table 2.B (with reference to speaking skills). Furthermore, the relationship between the two variables for both genders was highly correlative (females: $r=0.729$; males $r=0.6585$ ).

Table 2.D: the relationship between students' S.E and final exam outcomes according to gender

\begin{tabular}{|c|c|c|c|c|c|}
\hline Gender & Variable & M (\%) & P & Result & R \\
\hline & S.E & 64.83 & & & \\
\hline $\begin{array}{c}\text { Females } \\
(\mathrm{n}=118)\end{array}$ & & & 0.187092 & $\begin{array}{c}\text { Not Sig } \\
\mathrm{p}<.05\end{array}$ & 0.6743 \\
\hline & Final exam & 67.44 & & & \\
\hline & S.E & 61.11 & & & \\
\hline $\begin{array}{c}\text { Males } \\
(\mathrm{n}=90)\end{array}$ & & & 0.378034 & $\begin{array}{c}\text { Not Sig } \\
\mathrm{p}<.05\end{array}$ & 0.6995 \\
\hline & Final exam & 60.04 & & & \\
\hline
\end{tabular}

With respect to final examinations, Table 2.D displays data very comparable to those of Table 2.C (regarding mid-term exams); whereby both female and male students reported efficacy beliefs that closely represented their final examination scores, as reflected in similar $\mathrm{P}$ and $\mathrm{R}$ readings in both tables. Therefore, neither the weight of the assessment nor the notion of time affects the level of confidence in anticipated levels of performance or final grade outcomes as far as gender is concerned.

Table 3.A: the relationship between students' S.E and grade outcomes according to faculty of study

\begin{tabular}{|c|c|c|c|c|c|}
\hline Faculty & Variable & M (\%) & $\mathbf{P}$ & Result & $\mathbf{R}$ \\
\hline & S.E & 82.17 & & & \\
\hline \multirow[t]{3}{*}{$\begin{array}{c}\text { Vets } \\
(\mathrm{n}=60)\end{array}$} & & & 0.004539 & $\begin{array}{c}\text { Sig } \\
\mathrm{p}<.05\end{array}$ & 0.5372 \\
\hline & Grade & 87.08 & & & \\
\hline & S.E & 61.03 & & & \\
\hline \multirow[t]{3}{*}{$\begin{array}{c}\text { Business } \\
(\mathrm{n}=77)\end{array}$} & & & 0.416598 & $\begin{array}{l}\text { Not Sig } \\
\mathrm{p}<.05\end{array}$ & 0.6542 \\
\hline & Grade & 60.45 & & & \\
\hline & S.E & 63.94 & & & \\
\hline \multirow{2}{*}{$\begin{array}{c}\text { Engineers } \\
(\mathrm{n}=71)\end{array}$} & & & 0.002395 & $\begin{array}{c}\text { Sig } \\
\mathrm{p}<.05\end{array}$ & 0.5304 \\
\hline & Grade & 55.01 & & & \\
\hline
\end{tabular}


English proficiency varied greatly as a function of the students' academic background. The inferential relationship that comes to light in Table 3.A is that higher levels of English ability reflect in more conservative judgments of self-efficacy beliefs concerning academic capabilities. For instance, the vets significantly underestimated their competences proportionate to their respective attainments (sig: $p<0.05$ ); which interfered with the degree of linearity between the two variables $(r=0.55372)$. As for business students, the mid-ability cluster, the average value of their self-efficacy judgments closely resembled their performance attainments

(not sig: $\mathrm{p}<0.05$ ), and correlated more closely $(\mathrm{r}=0.6542)$. The lowest performing group were over generous in their personal appraisals of self-efficacy, as respective performance was significantly lower than declarations of personal efficacy would have suggested.

Table 3.B: relationship between students' S.E and speaking proficiency according to faculty

\begin{tabular}{|c|c|c|c|c|c|}
\hline Faculty & Variable & M (\%) & $\mathbf{P}$ & Result & $\mathbf{R}$ \\
\hline & S.E & 69.678 & & & \\
\hline \multirow[t]{3}{*}{$\begin{array}{c}\text { Vets } \\
(n=60)\end{array}$} & & & $<.01$ & $\begin{array}{l}\text { Sig } \\
\mathrm{p}<.05\end{array}$ & 0.43 \\
\hline & Speaking & 84.62 & & & \\
\hline & S.E & 51.68 & & & \\
\hline \multirow[t]{3}{*}{$\begin{array}{c}\text { Business } \\
(\mathrm{n}=77)\end{array}$} & & & 0.016 & $\begin{array}{c}\text { Sig } \\
\mathrm{p}<.05\end{array}$ & 0.4635 \\
\hline & Speaking & 65.98 & & & \\
\hline & S.E & 56.33 & & & \\
\hline \multirow[t]{2}{*}{$\begin{array}{c}\text { Engineers } \\
(\mathrm{n}=71)\end{array}$} & & & 0.441272 & $\begin{array}{l}\text { Not Sig } \\
\mathrm{p}<.05\end{array}$ & 0.4936 \\
\hline & Speaking & 56.85 & & & \\
\hline
\end{tabular}

Cross-faculty comparisons in Table 3.B show that personal efficacy beliefs relative to speaking skills also are inconsistent with performance outcomes owing to low levels of reported self-efficacy (with the exception of engineers). $R$ values across all sub-categories imply a much weaker degree of linearity, even though mean self-efficacy judgments among engineers appeared representative of average speaking attainments (not sig: $\mathrm{p}<0.05$ ); nonetheless, an equally modest correlation between variables $(r=0.4936)$ infers ample variability of data within this sub-group.

Table 3.C: the relationship between students' S.E and mid-term scores according to faculty

\begin{tabular}{|c|c|c|c|c|c|}
\hline Faculty & Variable & M (\%) & $\mathbf{P}$ & Result & $\mathbf{R}$ \\
\hline & S.E & 78.17 & & & \\
\hline \multirow[t]{3}{*}{$\begin{array}{c}\text { Vets } \\
(\mathrm{n}=60)\end{array}$} & & & $<.01$ & $\begin{array}{c}\text { Sig } \\
\mathrm{p}<.05\end{array}$ & 0.3059 \\
\hline & Mid-term & 89.15 & & & \\
\hline & S.E & 53.51 & & & \\
\hline \multirow[t]{3}{*}{$\begin{array}{c}\text { Business } \\
(\mathrm{n}=77)\end{array}$} & & & 0.464015 & $\begin{array}{l}\text { Not Sig } \\
\mathrm{p}<.05\end{array}$ & 0.6139 \\
\hline & Mid-term & 53.27 & & & \\
\hline & S.E & 59.3 & & & \\
\hline \multirow[t]{2}{*}{$\begin{array}{c}\text { Engineers } \\
(\mathrm{n}=71)\end{array}$} & & & 0.09958 & $\begin{array}{l}\text { Not Sig } \\
\mathrm{p}<.05\end{array}$ & 0.5729 \\
\hline & Mid-term & 55.37 & & & \\
\hline
\end{tabular}

Table 3.C confirms that higher performing students (vets) once again significantly underestimated their ability to secure high grades in the mid-term test (sig: $\mathrm{p}<0.05)$, diluting the correlation between the two variables $(\mathrm{r}=0.3059)$; whereas business and engineering students estimated their abilities more accurately $(r=0.6139$ and $r=0.5729$ respectively). The most remarkable inconsistency in this domain specific calculation is that both efficacy measures and performance results among the mid-ability group (business) were inferior to those of the conventionally below average group (engineers). The next question will look at whether this performance related inconsistency also occurs in the final examination results.

Table 3.D: the relationship between students' S.E and final exam results according to faculty

\begin{tabular}{|c|c|c|c|c|c|}
\hline Faculty & Variable & M (\%) & $\mathbf{P}$ & Result & $\mathbf{R}$ \\
\hline & S.E & 77.5 & & & \\
\hline \multirow[t]{3}{*}{ Vets } & & & $<.01$ & $\begin{array}{c}\text { Sig } \\
\mathrm{p}<.05\end{array}$ & 0.4374 \\
\hline & Final exam & 89.28 & & & \\
\hline & S.E & 54.67 & & & \\
\hline \multirow[t]{3}{*}{ Business } & & & 0.331023 & $\begin{array}{c}\text { Not Sig } \\
\mathrm{p}<.05\end{array}$ & 0.6098 \\
\hline & Final exam & 56.07 & & & \\
\hline & S.E & 60.42 & & & \\
\hline \multirow[t]{2}{*}{ Engineers } & & & 0.013546 & $\begin{array}{c}\text { Sig } \\
\mathrm{p}<.05\end{array}$ & 0.6143 \\
\hline & Final exam & 51.92 & & & \\
\hline
\end{tabular}

Table 3.D presents a more consistent pattern of results in the sense that the higher performers (vets) were 
repeatedly over modest in their appraisals of self-efficacy, which yet again, contributed to a comparatively weaker correlation $(r=0.4374)$. Furthermore, the mid-tier group (business) self-reported beliefs of self-efficacy that closely matched respective performance outcomes, also displaying a positively correlation $(r=0.6098)$. In addition, constant with most prior calculations, the lowest performing group (engineers) overstated their beliefs relative to their potential attainments (sig: $\mathrm{p}<0.05)$, despite a strong correlation between variables $(\mathrm{r}=0.6143)$.

\subsection{Further discussion}

The size, overall demographic balance and the academic diversity of the sample provided ample scope for informative calculations and meta-analysis. In accordance with the discoveries discussed in the review of prior studies, the findings in this paper add firm support to the notion that, as a general concept, self-efficacy beliefs correlate positively with academic performance. Nonetheless, upon deeper reflection, a number of discrepancies came to surface and necessitate further discussion.

First of all, the demographics of the sample population included in this paper are very different from those of the U.K primary education setting, yet the data pertaining to the relationship between self-efficacy and academic performance largely coincided. Similar to this study, girls at the primary school reported higher levels of self-efficacy than boys, and, performed to significantly higher levels in their respective assessments. Whereas, the university related study in Albania suggested that, on the basis of gender, there was no significant difference in self-efficacy judgments, and, only minor differences were noted in academic performance; despite comprising similar demographics to the respondents studied in this paper. One plausible explanation is that the Albanian study utilised efficacy scales with a limited continuum of $1-4$, thus restricting response possibilities.

With reference to levels of specificity, the research at elementary level concluded that, the more specific the measure of self-efficacy, the greater the correlation with respective performance outcomes (general science $r=0.60$, domain specific to science $r=0.65$, and, task specific to science $r=0.72$ ). The findings in this paper did not coincide with the elementary study in this regard, but did nonetheless contribute to validating the predictive utility of selfefficacy judgments as a more subject wide measure $(r=0.692)$.

However, in the context of this research paper, the results brought to light from both subject and domain specific measures among sub-groups showed that vet students continuously underestimated their overall capabilities, and conversely, the engineers habitually overstated their potential. One conceivable elucidation is that by isolating subgroups that are similar in ability, and with comparable cognitions, less variability can be taken into account. By following similar lines of thought, supposing one particular sub-group collectively underestimates or overstates its capabilities in relation to its attainment potential, the accuracy of efficacy scales risks being understated. Moreover, populations are comprised of individuals of diverse character, beliefs and capabilities, and, it is the scale and diversity of the sample that is more likely to provide truer results.

\section{Conclusion}

Notwithstanding the theory that domain specific self-efficacy scales purportedly offer greater levels of predictive value (Bandura, 2006), the results derived from this research paper discovered that subject-related self-efficacy measures comprising a varied population appeared to offer a more reliable indication of potential performance. In general terms therefore, concerted efforts to create befitting opportunities for mastery experiences and coping skills development among students in order to increase efficacy levels would seemingly foster greater academic acumen. Efficacy scales for subject related questions will help educators to understand students' capabilities, whereas domain specific measures will help to determine low-confidence areas in greater need of attention; guiding teachers in curricular planning and implementation.

\subsection{Suggestions for future research}

Further investigative action could be encouraged to ascertain the reasons governing misappraisals of efficacy judgments in relation to speaking skills. Other variables that may warrant further investigation to help explicate this phenomenon could include: (1) students' attitudes towards (speaking) English, (2) the perceived level of importance of English, (3) level of enjoyment in studying the subject, and, (4) potential affective issues that may cloud efficacy judgments and potentially hinder academic achievement.

Secondly, although macro skills could not be studied in this paper, further research to investigate IELTS candidates' efficacy beliefs in macro skills may constitute a solid proposal for subsequent research, on the grounds that students are assessed across all four areas on a scale of 1-9, (although 1-7 may be considered a more realistic continuum). However, data acquisition may prove to be complicated given that particular test centres conduct specific assessments, often in separate countries, combined with the issue that data is regarded as highly sensitive and confidential; thus, this potentially telling line of enquiry lies out of bounds for the vast majority of researchers.

\section{References}

1. Bandura, A. (1977). Self-efficacy: Toward a unifying theory of behavioral change. Psychological Review, (84), 191-215.

2. Bandura, A. (1984). Recycling misconceptions of perceived self-efficacy. Cognitive Therapy and Research, (8), 231-

255. 
3. Bandura, A. (1986). Social foundations of thought and action: A social cognitive theory. Englewood Cliffs, NJ: Prentice-Hall.

4. Bandura, A. (1991a). Self-efficacy mechanism in physiological activation and health-promoting behavior. In J. Madden, IV (Ed.), Neurobiology of learning, emotion and affect (229-270). New York: Raven.

5. Bandura, A. (1994). Self-efficacy. In V. S. Ramachaudran (Ed.), Encyclopedia of human behavior, (4), 71-81. New York: Academic Press.

6. Bandura, A. (1995). Self-efficacy in changing societies. (Ed.). New York: Cambridge University Press.

7. Bandura, A. (1996). Regulation of cognitive processes through perceived self-efficacy. In G. H. Jennings \& D. Belanger (Eds.), Passages beyond the gate: A Jungian approach to understanding the nature of American psychology at the dawn of the new millennium (96-107). Needham Heights, MA: Simon \& Schuster. [Reprint of Bandura, A. (1989)].

8. Bandura, A. (1997). Self-efficacy: The exercise of control. New York: Freeman.

9. Bandura, A. (2006). Self-Efficacy Beliefs of Adolescents. Guide for constructing self-efficacy scales (307-337).

10. Britner, S. L., \& Pajares, F. (2001) Self-efficacy beliefs, motivation, race and gender in school science. Journal of women and Minorities in Science and Engineering, (7), 271-285.

11. Bussey, K., \& Bandura, A. (1999). Social cognitive theory of gender development and differentiation. Psychology Review, (106), 676-713.

12. Eisenberg, N., Martin, C. L., \& Fabes, R. A. (1996). Gender development and gender effects. In D. C. Berliner \& R. C. Calfee (Eds.), Handbook of educational psychology (358-396). New York: Simon \& Schuster Macmillan.

13. Pajares, F. (1996). Self-efficacy Beliefs in Academic Settings. Review of Educational Research. 66 (4), 543 - 578.

14. Pajares, F., Hartley, J., \& Valiante, G. (2001). Response format in writing self-efficacy assessment: Greater discrimination increases prediction. Measurement and Evaluation in Counseling and Development, 33 (4), 214-221.

15. Pajares, F., \& Schunk, D. H. (2001). Self-beliefs and school success: Self-efficacy, self-concept, and school achievement. In R. J. Riding \& S. G. Rayner (Eds.), International perspectives on individual differences, (2). Selfperception (239-265). Ablex Publishing.

16. Pajares, F., \& Valiante, G. (1999). Grade level and gender differences in the writing self-beliefs of middle school students. Contemporary Educational Psychology, (24), 390-405.

17. Wigfield, A., Eccles, J. S., \& Pintrich, P. R. (1996). Development between the ages of 11 and 25. In D. C. Berliner \& R. C. Calfee (Eds.), Handbook of educational psychology (148-185). New York: Macmillan. 